\title{
Correlation Research of Shanghai Index and the BDI
}

\author{
Shixin Zhang ${ }^{1, a}$ and Lijuan Pei ${ }^{2, b, ~ * ~}$ \\ ${ }^{1}$ Lanzhou University of Technology, China \\ ${ }^{2}$ Lanzhou University of Technology, China \\ a506338087@qq.com, ${ }^{\text {b } 1150289398 @ q q . c o m ~}$
}

Keywords: Shanghai Index; BDI; Correlation and regression analysis; ARIMA model

\begin{abstract}
This article selects data from 2000 to 2017, using correlation and regression analysis methods to analyze the correlation of Shanghai index and the BDI, and found that there is an obvious correlation. The ARIMA model is used to predict the two, and the two have the tendency to rise in the short term, and the two have a leading and backward relationship. Economic globalization and the "Chinese factor" are the fundamental driving forces to promote the relationship. Understanding the relationship between them can help investors, enterprises and governments make better decisions.
\end{abstract}

\section{Introduction}

Economic globalization is manifested in the global distribution of raw materials, capital, technology, labor force, and distribution of products and services worldwide. The acceleration of economic globalization has strengthened the transmission of economies, while the risk level of economic development has also increased. At present, the world economy is developing rapidly and rapidly, and the process of world economic integration is becoming more and more obvious. Finance and investment are undoubtedly the hot topics of the moment. Although the capital market has experienced a great deal of ups and downs in the past century, people's enthusiasm for stocks and investment has increased. Because now the mature capital market, investment is not as conservative as before, so the researchers from all over the world, investors in capital market, stock index research also more and more. As the benchmark index of China's stock market, the Shanghai index has undergone many years of correction and improvement, which can reflect the macro and micro economic situation of China to some extent. Therefore, the fluctuation rule and research of Shanghai index are more and more concerned.

The BDI is a barometer that reflects the trend of international dry bulk transport market and is also a leading indicator of international trade. It is of great significance to discuss its fluctuation rule. As a result, the yield and volatility of the BDI are getting more and more attention. By analyzing the fluctuation of the dry bulk freight index, the operator grasps the fluctuation rule, grasps the market dynamics and implements the corresponding measures, thus reasonably avoiding the market risk. In general, BDI will rise, and the share price of transport shares will rise. Assuming the demand for raw materials is still increasing, but the supply of freighters increases and the market for bad freight is broken, BDI will fall, and the share price of transport shares will fall. Thus, the impact of the BDI on share prices is crucial.

The investment environment of each country is obviously affected by the global economic environment, and there is some inherent connection between the fluctuation of stock index and the BDI. The BDI as commodities trading shipping economic indicators, is an indicator of international commodity trade situation, with the global economic boom boom, entity enterprise demand for raw materials prices high and low. The current change of the index fluctuates with the fluctuation of economic trade. In the context of globalization, the imbalance of global trade aggravates the risks of domestic real economy. At the same time, the capital market is an important financing channel for real enterprises, which is more and more volatile. Thus it can be seen that the BDI and Shanghai index to study the current China's commodity trade and the relationship between the real economy and financial markets, to predict future movements of the BDI and Shanghai index and the 
promotion of China's economic development and upgrading of industrial structure has important guiding significance.

\section{Literature References}

The stock market has certain volatility, the stock price fluctuates, the long-term stock price trend is volatile development. Later, people gradually discovered that the volatility of a stock market was not only affected by the various factors in the country, but also influenced by other market factors and the international environment. In the year 2002, Darrat and zhong[1] examined the co-integration of the United States and the asia-pacific region and Japan, and found that they had a long-term equilibrium, in which the U.S. stock market played a key role. In 2003, Connolly and Wang[2] did a lot of research on the interactivity of the stock market, and they mainly studied the interactivity of the stock market between public information and other information that was not basic. The BDI is a leading indicator of international trade, and there is a lot of research on it. Based on the analysis of freight rates ,Kavussanos and Visvikis (2006)[3] pointed out that the price fluctuation of dry bulk shipping market was large and there were high risks. Yao-Jen Hsiao, Heng-Chih Chou and Chun-Chou Wu (2014) [4]used cointegration analysis, Granger causality test and GARCH-BEKK model to analyze the relationship between BDI and China containerized freight index (CCFI). Using the ARCH model, Qinghui Chen (2004)[5] analyzed the volatility of the freight index of international dry bulk shipping market, and concluded that there was an asymmetric information in the international dry bulk market.

However, most of the above scholars study the interactivity of stock market fluctuation separately, or study the change rule of BDI and its influencing factors separately. Few scholars have studied the relationship between BDI and stocks. In recent years, some scholars in China have focused on the close relationship between the two, and have studied and analyzed the relationship between the BDI and the Shanghai index. Guo-long Lin, south Korean, Ye Shanchun (2013)[6]using Johansen cointegration test and Granger causality test method to analysis the Shanghai index and the BDI in 2006-2011, and found that there exists long-term cointegration relationship between two index and Granger causality. Bin Liu. (2010)[7] analyzed the graph and scatter plot of BDI index and Shanghai index before and after the financial crisis. It is found that the BDI has positive correlation with the Shanghai index, and the Shanghai index is more than the BDI .Based on the previous research results, this paper analyzes the correlation between BDI and Shanghai index. The ARIMA model is used to predict the future trend of BDI and Shanghai index.

\section{The empirical research}

Correlation between BDI and Shanghai index (monthly data). Because the BDI and the Shanghai index have a large annual data span, and it will lead to an error in the analysis results. Therefore, this paper selects the monthly data of the BDI and the Shanghai index (monthly average), and analyzes the correlation of BDI and Shanghai index.

Table 1 Correlation analysis

\begin{tabular}{|l|c|c|c|}
\hline \multicolumn{4}{|c|}{ Correlation analysis } \\
\hline \multirow{2}{*}{ BDI } & & BDI & $\begin{array}{l}\text { Shanghai } \\
\text { index }\end{array}$ \\
& Pearson & 1 & $.271^{* *}$ \\
\cline { 2 - 4 } & $\mathrm{P}$. & & .000 \\
\cline { 2 - 4 } & $\mathrm{N}$ & 208 & 208 \\
\hline $\begin{array}{l}\text { Shanghai } \\
\text { index }\end{array}$ & Pearson & $.271^{* *}$ & 1 \\
\cline { 2 - 4 } & $\mathrm{P}$. & .000 & \\
\cline { 2 - 4 } & $\mathrm{N}$ & 208 & 208 \\
\hline
\end{tabular}


Table 1 shows that the $\mathrm{P}$ value of the bilateral significance test is 0.000 , which is less than 0.01 . Therefore, the rejection of the original hypothesis indicates that the BDI index is significantly correlated with the Shanghai index. There is a clear correlation between the two.

Table 2 Regression analysis

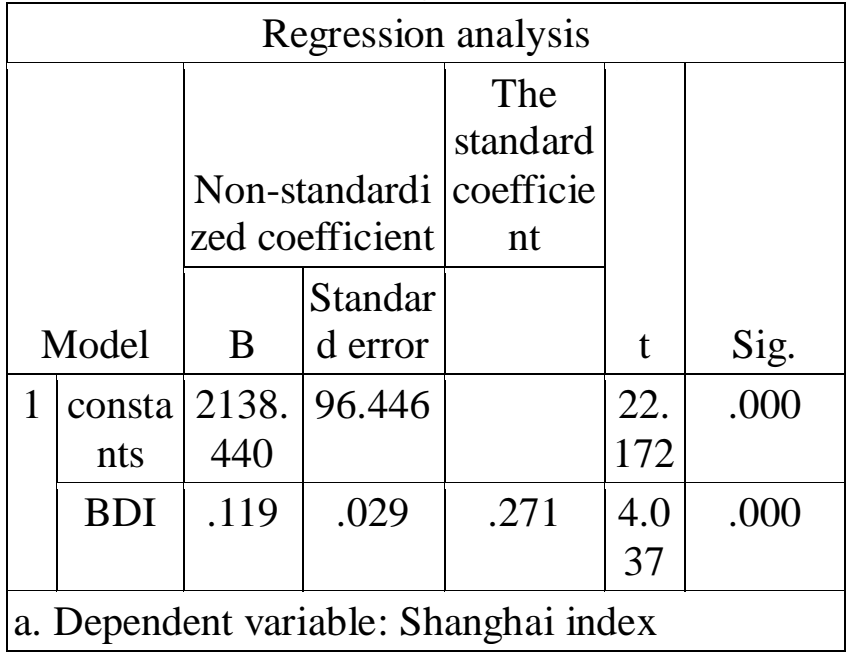

Table 3 Goodness of Fit

\begin{tabular}{|c|c|c|c|c|}
\hline \multicolumn{7}{|c|}{ Goodness of Fit } \\
\hline & & & Adjusted & $\begin{array}{c}\text { Standard } \\
\text { Model }\end{array}$ \\
\hline 1 & R & $R^{2}$ & .069 & 919.1559925 \\
& $.271 \mathrm{a}$ & .073 & & \\
\hline a. Predictive variables: (constant), BDI. & \\
\hline
\end{tabular}

Table 2 shows that the $\mathrm{P}$ value of bilateral test is $0.00 . \mathrm{P}$ is less than 0.05 , so reject the original hypothesis. It shows that the BDI index is significantly correlated with the Shanghai index. At the same time, the regression equation can be obtained: $y=2138.44+0.119 x$ ( $y$ : Shanghai index, $x$ : BDI).

As shown in table 3, the adjusted $\mathrm{R}$ squared is 0.069. It indicates that 69 percent of the fluctuation of the Shanghai index is caused by BDI, which indicates that the established regression equation is reasonable and the fitting is good. 
The Baltic index and the Shanghai index forecast.

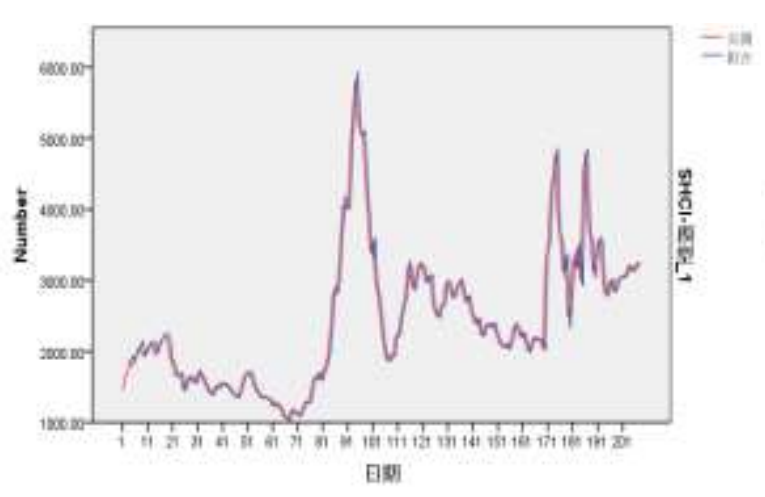

Figure 1. BDI forecasting

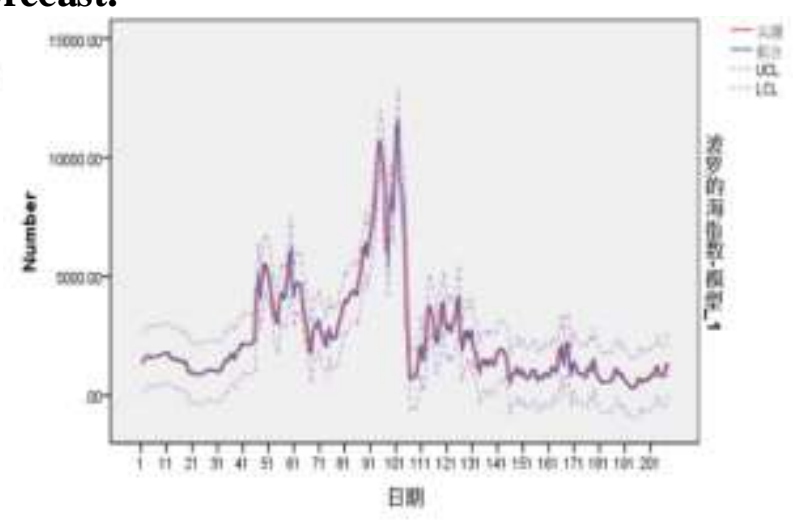

Figure 2. Shanghai index forecasting

Can be seen from Fig.1, Fig. 2, the Baltic sea and the Shanghai index in the future in the short term has obvious rising trend, and the Baltic index rising velocity significantly faster than the Shanghai composite index rising velocity. It can also be proved that there is a leading - lagging relationship between the two. During the boom, BDI was ahead of the Shanghai index.

\section{Conclusion}

In the context of economic globalization, the relationship between markets is complicated and the world market is closely linked. In particular, the transmission mechanism between the markets must be well understood in order to better guide the behavior of people. As a microcosm of the capital market, the Shanghai composite index has become more and more influential in the world economy. This is not just an investment Angle, but a country's economic development level cannot be ignored. With the maturing of China's capital market, the information contained in the Shanghai composite index will be further deepened, and the impact on the external environment will be more responsive. The BDI index, as the "barometer" of the international dry bulk market, can reflect the cost level of world economic development from the side. The BDI index is closely linked to the Shanghai composite index, which is strongly influenced by the "Chinese factor". Correlation and regression analysis confirmed the correlation between the two. Through the prediction of BDI and Shanghai index, it shows that both of them have a tendency to rise in the short term, and the relationship between them is leading and lagging. It also provides the decision support for our country to build an international shipping center and financial center to some extent.

\section{References}

[1] DaiTat. A and M. Zhong: Financial Review, Vol. 37 (2002), p. 35.

[2] Connolly R. A and Wang F.A: Pacific -Basin Finance Journal, (2003). p.23 .

[3] Kavussanos and I.D.Visvikis: Maritime Policy \& Management, Vol. 33.(2006).No.3, p.233.

[4] Y.J.Hsiao, H.C.Chou and C.C.Wu: Maritime Policy \& Management,Vol. 41.(2014).No.7, p.697.

[5] Q.H. Chen:Research on the fluctuation of freight index in international dry bulk shipping market(MS.,Dalian Maritime University,China 2004), p. 01.(In Chinese)

[6] G.L.Liu, J.Han and S.Ye: Commercial research, (2013).No.4, p.122.(In Chinese)

[7] B.Liu, C.Liu and X.Y.Liu.:Dalian maritime university journal, (2010).No.3,p.35. 